\title{
Corrigendum: Scene perception in posterior cortical atrophy: categorization, description and fixation patterns
}

\section{Timothy J. Shakespeare ${ }^{1 *}$, Keir X. X. Yong ${ }^{1}$, Chris Frost ${ }^{2}$, Lois G. Kim ${ }^{2}$, Elizabeth K. Warrington ${ }^{1}$ and Sebastian J. Crutch ${ }^{1}$}

${ }^{7}$ Dementia Research Centre, Institute of Neurology, University College London, London, UK

${ }^{2}$ Department of Medical Statistics, London School of Hygiene and Tropical Medicine, London, UK

${ }^{*}$ Correspondence: tim.shakespeare.10@ucl.ac.uk

\section{Edited and reviewed by:}

Magdalena Chechlacz, University of Oxford, UK

Keywords: psychology, eye tracking, Agnosia, Alzheimer's disease (AD), scene perception

\section{A corrigendum on}

Scene perception in posterior cortical atrophy: categorization, description and fixation patterns

by Shakespeare, T. J., Yong, K. X. X., Frost, C., Kim, L. G., Warrington, E. K., and
Crutch, S. J. (2013). Front. Hum. Neurosci. 7:621. doi: 10.3389/fnhum.2013.00621

The legend of Figure 6 is labeled incorrectly. Contrary to the legend, the blue bars refer to "Age Matched Controls" and

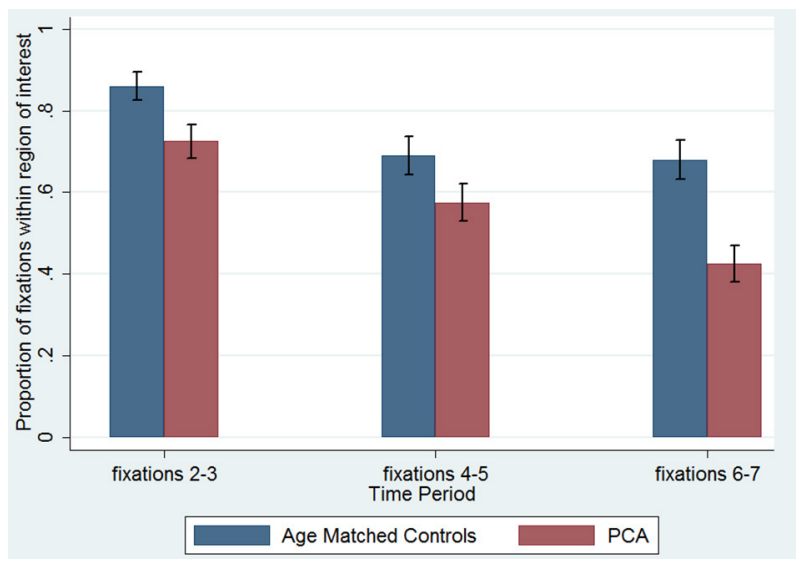

FIGURE 6 | Proportion of fixations inside the young control defined region of interest, by time period. The first fixation is omitted as it is predetermined by a central drift correction at the start of each trial. Error bars show standard error.

the red bars refer to "PCA." The results as described in the main text remain unchanged.

The corrected version of Figure 6 is presented below:

Conflict of Interest Statement: The authors declare that the research was conducted in the absence of any commercial or financial relationships that could be construed as a potential conflict of interest.

Received: 17 October 2014; accepted: 23 October 2014; published online: 11 November 2014.

Citation: Shakespeare TJ, Yong KXX, Frost C, Kim LG, Warrington EK and Crutch SJ (2014) Corrigendum: Scene perception in posterior cortical atrophy: categorization, description and fixation patterns. Front. Hum. Neurosci. 8:908. doi: 10.3389/fnhum.2014.00908

This article was submitted to the journal Frontiers in Human Neuroscience.

Copyright (c) 2014 Shakespeare, Yong, Frost, Kim, Warrington and Crutch. This is an open-access article distributed under the terms of the Creative Commons Attribution License (CC BY). The use, distribution or reproduction in other forums is permitted, provided the original author(s) or licensor are credited and that the original publication in this journal is cited, in accordance with accepted academic practice. No use, distribution or reproduction is permitted which does not comply with these terms. 